\title{
Construyendo el camino de la transformación personal y colectiva: El inicio de una experiencia de investigación-acción
}

\section{Building the Path of Personal and Collective Transformation: the Beginning of an Action-Research Experience}

\author{
Ana Lucía Chaves Álvarez ${ }^{1}$ \\ División de Educación Básica del \\ Centro de Investigación y Docencia en Educación \\ Universidad Nacional \\ Heredia, Costa Rica \\ alchavesalvarez@hotmail.es
}

Recibido 26 de julio de 2011 • Aceptado 26 de agosto de 2011

Resumen. Un proceso de investigación-acción se caracteriza por la participación de diferentes personas con el fin de buscar una transformación, tanto personal como colectiva, así como por analizar las propias realidades para mejorarlas. Este ensayo presenta la experiencia del inicio de una investigación-acción realizada por la autora, en la que se analiza una situación propia de su práctica laboral cotidiana.

Palabras claves. Investigación-acción, reflexión, transformación.

Abstract. An action-research process is characterized by the participation of different people to find a personal and collective transformation, and by analyzing our own realities to improve them. This paper presents the experience of starting an action-research process, conducted by the author, analyzing her own everyday working practice situation.

Keywords. Action-research, reflection, transformation.

Licenciada en Pedagogía con énfasis en Educación Preescolar (UNA). Experiencia docente en instituciones educativas costarricenses. Académica de la División de Educación Básica, del Centro de Investigación y Docencia en Educación de la Universidad Nacional, Costa Rica. Ha trabajado como miembro del equipo del Proyecto de Acreditación de la División de Educación Básica, del Centro de Investigación y Docencia en Educación, de la Universidad Nacional, así como en los procesos de intervención pedagógica del I Nivel de Diplomado de la Carrera de Pedagogía con énfasis en Educación Preescolar. Es estudiante de la Maestría en Pedagogía con énfasis en Desarrollo y Atención Integral de la Primera Infancia, de la Universidad Nacional de Costa Rica. 
Pero en el acontecimiento "lo que muchas veces nos encontramos no es algo que necesariamente habría que encontrar; lo que sucede no era algo que tenía que suceder". Esta "no necesariedad" propia de todo acontecimiento que es, sobre todo, "un suceder, un fluir" es lo que permitía no sólo obtener unos resultados, encontrarse con unos logros, sino también la sorpresa de nuevas posibilidades, la acogida de lo inesperado. (Toro, 2005, pp. 42-43)

\section{Introducción}

Iniciar un proceso dentro del enfoque de investigación-acción es iniciar una aventura hacia las preguntas sin respuesta, los procesos inacabados, los cambios, el movimiento de los procesos, la riqueza de las relaciones interpersonales y la construcción de aprendizajes, tanto individuales como colectivos. En este sentido, me siento motivada a desarrollar esta investigación, que se convierte en mi Trabajo Final de Graduación de la Maestría en Pedagogía con énfasis en el Desarrollo y Atención Integral de la Primera Infancia de la Universidad Nacional.

El presente ensayo tiene como propósito compartir el inicio de la experiencia vivida en la investigación-acción titulada Perspectiva de un grupo de estudiantes de Bachillerato y Licenciatura de la División de Educación Básica (DEB) sobre la pertinencia del Plan de Estudios de la Carrera de Pedagogía con énfasis en Educación Preescolar (CPEP), en la formación de docentes de educación preescolar para la atención educativa de niñas y niños menores de cinco años. Como bien lo mencioné anteriormente, considero importante destacar que lo que se presenta en las siguientes páginas es el surgimiento de esta investigación-acción, en el entendido de que no será, sino hasta en un segundo ensayo, en donde presentaré los resultados finales de la misma. Mi intención, al plasmar este comienzo, es compartir con el lector y la lectora, el camino hacia la transformación personal y colectiva de la que hablo en el título y, al mismo tiempo, motivarlo y motivarla a aventurarse en un proceso de investigación-acción.

\section{Preparando la maleta para aventurarme al camino, todo lo que necesito llevar...}

Rodríguez, citado por Blández (2000), destaca que la investigación-acción es un “(...) modelo de investigación dentro del paradigma cualitativo que observa y estudia, reflexiva y participativamente, una situación social para mejorarla" (p. 23). De este modo, abro la puerta hacia un tipo de investigación que me brinda la posibilidad de ser un sujeto activo, participativo y transformador de mi propia práctica laboral.

$\mathrm{Al}$ empezar con este camino hacia la transformación, empiezo a descubrirme a mí misma, a conocer más acerca de lo que hago y acerca de quién soy y, poco a poco, voy comprendiendo que una investigación-acción no es únicamente la búsqueda de una transformación de la realidad, lo cual considero muy importante, sino que, también, implica una transformación de mí misma, de mis esquemas y estructuras mentales, de mis "certezas" que ya se convirtieron en preguntas, de lo que soy y de lo que hago en mi lugar de trabajo.

Creo importante señalar que este proceso de transformación lo he experimentado, desde que me siento a redactar estas líneas, a partir de mis propias reflexiones personales sobre hacia dónde voy y qué es lo que quiero $\mathrm{y}$, por supuesto, a partir de las interacciones con 
mis estudiantes universitarias. Todo esto me posiciona en un lugar que me permite aprender de todo: de las interacciones, del ambiente, de los tiempos, de las risas, de las palabras de apoyo, y aunque tengo incertidumbres, miedos, dudas y contradicciones, cada vez me voy empoderando más de lo que estoy haciendo y, por consiguiente, voy construyendo ese camino de transformación individual y colectiva. Es así como se puede plantear el argumento de Freire (2006), quien destaca que como seres humanos tenemos la capacidad de transformar el mundo y que, precisamente, la responsabilidad de los pedagogos es propiciar espacios de transformación y no de quietud o pasividad.

De este modo, puedo mencionar que mi investigación se basa en un proceso de recopilación de información y análisis, sobre las perspectivas que tienen estudiantes de la Carrera de Pedagogía con énfasis en Educación Preescolar (CPEP), sobre la formación docente en cuanto a la atención educativa integral de niños y niñas menores de cinco años. Es decir, lo que se pretende es conocer la opinión estudiantil acerca de qué tan preparadas y capacitadas egresan las estudiantes para atender educativamente poblaciones infantiles menores de cinco años.

Sin duda alguna, esto tiene un impacto personal para mí, ya que en primer lugar, soy graduada de esta misma Carrera y mi primera experiencia laboral fue con niños y niñas de tres años, me enfrenté, así, a una situación nueva en la que en muchas situaciones no sabía qué hacer, aún cuando únicamente me faltaba terminar con mi Trabajo Final de Graduación de Licenciatura. Otra de las razones por las cuales esta investigación tiene una relevancia personal y significativa se basa en el hecho de que soy parte de la CPEP y, como académica, me ha surgido la inquietud con respecto al problema planteado anteriormente; asimismo, he tenido la oportunidad de escuchar los comentarios y manifestaciones de mis estudiantes al respecto.

De esta manera es como surge el problema de mi investigación, el cual pretende aclarar desde la perspectiva de un grupo de estudiantes de la DEB: ¿qué pertinencia tiene el Plan de Estudios de la Carrera de Pedagogía con énfasis en Educación Preescolar para la formación de docentes de educación preescolar en la atención educativa de niñas y niños menores de cinco años?

En general, considero que este problema es parte de la dinámica de la CPEP. Se podría decir que ha sido tratado en diferentes espacios de reflexión académica, los cuales han surgido por las dinámicas que se están dando entre las estudiantes de la CPEP, al manifestar abiertamente la necesidad de una mayor capacitación sobre la atención pedagógica a niños y niñas menores de cinco, pero al mismo tiempo, a la luz de la realidad actual, que exige docentes cada vez más capacitados y preparados para atender la población infantil.

Peralta (2004) hace referencia a esto al plantear lo siguiente:

La educación inicial presenta nuevos desafíos para Latinoamérica. No solo se debe continuar ampliando e instalando este nivel educativo en las políticas y en los sistemas financieros y educacionales de nuestros países, donde aún hay grandes metas que alcanzar en función del derecho de los párvulos a una educación oportuna desde el nacimiento, sin que hay que avanzar hacia niveles importantes de calidad que aseguren la inversión que los programas implican, y que respondan al impacto que se desea de ellos. Esto último significa ser capaces de generar propuestas educativas que respondan a las características, necesidades y fortalezas de las niñas y niños de hoy, en un mundo que, al igual que ellos, ha cambiado y que genera nuevas situaciones y oportunidades. (p. 59) 
No obstante, aunque en la DEB se han dado estos espacios de reflexión, no se han hecho procesos de transformación documentados que, en la práctica, busquen un cambio positivo en la formación que están recibiendo las estudiantes, de manera que se confirme que puedan egresar con una formación que les permita atender niños y niñas menores de cinco años y, por lo tanto, para trabajar en diferentes espacios laborales.

Creo, entonces, que el problema puede y debe ser abordado tomando en cuenta la opinión de las estudiantes, quienes reciben la formación de la CPEP. De esta manera, se tendrán criterios básicos con el fin de que todos los sujetos participantes de la investigación, en este caso, la investigadora y las estudiantes, podamos construir o por qué no, reconstruir elementos para fortalecer el Plan de Estudios de la CPEP. Sin embargo, tengo muy claro el hecho de que estos elementos no pretenden ser exhaustivos ni acabados, por supuesto, que depende de las autoridades de la División de Educación Básica (DEB) y de la CPEP tomar en cuenta o no estos aspectos, para fortalecer dicho Plan.

Sí es importante mencionar, con determinación, que los insumos de la investigación servirán para mi desarrollo profesional como académica, ya que al escuchar las necesidades de las estudiantes en cuanto a la capacitación en la formación de niños menores de cinco años, puedo mejorar y enriquecer los cursos que imparto a lo interno de la CPEP. Por lo tanto, queda en evidencia el impacto personal que tiene la investigación, así como ese camino de transformación y renovación profesional -tanto individual como colectiva-, aspecto que resulta ser una característica fundamental de una investigación-acción (Olson, s. f.). De la misma forma, es claro que para iniciar un proceso dentro del enfoque de la investigación-acción, este debe ser cercano al investigador, partir de su realidad, de algo conocido; de lo contrario, carecerá de sentido y significatividad.

En este punto, considero necesario destacar el planteamiento de Jara (1994), quien aunque hace referencia específica a procesos de sistematización, estos están estrechamente vinculados con la investigación-acción y pueden aplicarse a la misma. Este autor indica que el punto de partida para sistematizar es “(...) partir de la propia práctica [negritas añadidas] (...) no se puede sistematizar algo que no se ha puesto en práctica previamente. (...) Sostenemos que sólo pueden sistematizar una experiencia, quienes han formado parte de ella (...)" (pp. 93-94).

Además de lo anterior, cabe señalar que el problema debe ser abordado en un espacio de reflexión y diálogo (Freire, 2005), se deben abrir vías de comunicación de manera que, tanto las estudiantes, como yo, podamos expresarnos libremente y opinar sobre la temática. Otro aspecto importante se basa en el planteamiento de Blández (2000) quien plantea que:

La investigación-acción implica una participación activa, en la que no sólo se aprende de los demás, sino que también los demás aprenden de ti. La experiencia, la opinión, la aportación de cada participante es con lo que se construye y se va desarrollando la investigación (...). (p. 24)

Por esto, considero pertinente propiciar espacios de reflexión individual y grupal, ya que son los que permiten la discusión y el compartir experiencias enriquecedoras para quienes participemos en el proceso. 


\section{¿Qué voy a hacer?}

Tal como mencioné anteriormente, destaco una vez más, que el tipo de estudio corresponde a una investigación-acción. Y, sin duda alguna, este tipo de investigación ha representado un proceso de crecimiento personal y profesional, porque al estar inmersa en él, se mueven mis estructuras, así como la rigidez que casi siempre me ha caracterizado y, entonces, se me abre una ventana de posibilidades para aprender, para disfrutar, para construir, para reflexionar, para equivocarme, para sentirme en confusión y en libertad (Olson, s. f.). Por esta razón, menciono en el título "construyendo el camino de la transformación individual y colectiva", porque esa transformación, aún en lo más pequeño y desde que inicié este proceso, ha empezado por mí.

Es así como va quedando en evidencia que, en un proceso de investigación-acción como este, yo como investigadora, me posiciono como una participante más, no como un simple agente externo que toma nota de lo que ocurre. Soy aprendiente, reflexiva, con dudas y temores, con la absoluta claridad y convicción de que en todo el proceso estoy aprendiendo del error y que nada, absolutamente nada, está diseñado a priori y queda inamovible; todo lo contrario, lo interesante de esta investigación es que, conforme uno va conociendo, observando, reflexionando, dialogando, actuando, escuchando y aprendiendo más, las cosas se van transformando, van cambiando, el movimiento es constante y, por eso, las certezas estructuradas y rígidas no tienen cabida aquí.

Precisamente, en cuanto a lo anterior, Elliot (2005) destaca que la investigación-acción se caracteriza por "(...) prácticas sociales que no tienen consecuencias estrictamente predecibles y cuyos resultados no pueden establecerse con claridad por estar abiertos a la creación individual y colectiva (...)” (p. 17). Entonces me pregunto, ¿no es al final de cuentas así como funcionamos los seres humanos?, pretender que las cosas quedan acabadas sin posibilidad de una transformación sería ir, según mi juicio, en contra de la naturaleza humana.

Sentirme identificada con lo que estoy haciendo, ser parte de la realidad, enfrentarme a contradicciones a partir de esto, también es parte del proceso de transformación al que he hecho referencia anteriormente. Así, queda claro que una investigación-acción asume, en general, a los individuos que participan en ella, como sujetos en construcción, que aprenden de lo que van haciendo, en un contexto y un ambiente que es conocido para ellos, que les genera emociones, sentimientos, afectos, identidad y sentido de pertenencia. Todo esto le da sentido al proceso investigativo y lo estoy experimentando.

Precisamente, esta construcción y transformación constante se relaciona con la premisa epistemológica de la investigación, la cual se basa en un proceso de construcción de respuestas no acabadas, para dar solución a lo que -creo- es una necesidad de la DEB, consistente en fortalecer los procesos de formación docente de la CPEP. En este sentido, la naturaleza de la relación sujetoobjeto de conocimiento es interactiva, dinámica y cambiante (Dobles, Zúñiga y García,1998).

Pretendo, entonces, que todos los sujetos participantes, por supuesto que incluida yo como parte del proceso, nos conozcamos más, disfrutemos, dialoguemos, reflexionemos, nos despojemos de los "velos" que asumen que tenemos el conocimiento, el poder o la autoridad y que mostremos la posibilidad de aprender de manera interrelacionada, para ir juntas construyendo diferentes preguntas y respuestas, las cuales, como ya lo he destacado, no serán definitivas ni absolutas, sino reconstruidas constantemente, abiertas a la duda y al error; pero, al final de cuentas, que permitan un crecimiento y un enriquecimiento de todas las que participemos en la aventura de conocer ese 
camino de transformación respecto a la pertinencia del Plan de Estudios de la Carrera de Pedagogía con énfasis en Educación Preescolar para la formación de docentes de educación preescolar dirigida a la atención educativa de niñas y niños menores de cinco años.

\section{Compañeras de la aventura en el camino de la transformación}

Un proceso investigativo dentro de un enfoque de investigación-acción se caracteriza, fundamental, por el trabajo con los demás. Según Kemmis y McTaggart, citados por Latorre (2007), la investigación acción se identifica por ser participativa, colaborativa y creadora de comunidades autocríticas de diferentes personas.

Ahora bien, pensar en aventurarse a un camino para la transformación implica asumir retos, desafíos, incertidumbres, preguntas sin respuesta, errores y equivocaciones. Cuando decidimos aventurarnos a algo, generalmente, no lo hacemos solas, siempre hay personas que están ahí para apoyarnos, para darnos palabras de apoyo, para impulsarnos o también para vivir con nosotros esa aventura. Podría decir, que si la obligatoriedad fuera característica de las aventuras, estas últimas no podrían considerarse como tales, cuando algo no sale bien, cuando algo sale bien, siempre hay personas que están ahí, pero por su propia voluntad, no porque nadie las obligó. Por consiguiente, sin duda alguna, cabe afirmar que en estas aventuras solo hay cabida para las invitaciones, no hay obligación de nada (Starico de Acomo, 1996), sino voluntad de querer ir, de querer sonreír, de querer disfrutar, de querer transformar y transformarse.

Uno de los errores, creo yo, es pensar que todas las personas van a querer aventurarse a participar y que todas se van a entusiasmar con estas invitaciones. En la realidad no es así, a unas personas les interesará quedarse en su casa descansando, a otras subirse a una montaña, a otras montarse en un barco, a otras correr muchos kilómetros y para comprender eso, hay que vivirlo y experimentarlo tal como yo tuve el privilegio de experimentarlo. Equivocadamente, pensé que a todas las estudiantes a las que quería hacer partícipes de la investigación les iba a interesar y querían caminar conmigo; sin embargo, no fue así, menos de la mitad quisieron involucrarse. Aunque al principio me sentí un poco frustrada, esa frustración me ayudó a abrir mis posibilidades, a crear otras estrategias y a buscar a otras compañeras de viaje, al mismo tiempo que esto ocurría, me di cuenta de que lo más importante de todo era la esencia de las personas que sí estuvieron dispuestas a participar y a aventurarse conmigo en esto.

La premisa paradigmática de la cantidad de participantes como condición para la validez y la confiabilidad cae, para dar cabida a la cualidad, las categorías de análisis y la profundización de la información, aspectos todos relevantes en un proceso de investigación acción (Dobles et al., 1998). Es así como, después de un proceso de invitación y en algunos casos de rechazo o aceptación, las que decidieron ser mis compañeras de viaje fueron ocho estudiantes de la CPEP.

Es importante destacar que tomé en cuenta al grupo de estudiantes de Licenciatura, porque están en el último año de la carrera y, por lo tanto, tienen una visión más completa del Plan de Estudios. Asimismo, escogí a las estudiantes de Bachillerato, porque cursan el penúltimo año de carrera y además por tener una visión casi completa del Plan de Estudios (solamente les falta un año y medio para terminar), porque trabajan con niños menores de cinco años, uno de los ejes centrales de la investigación. 
Ahora bien, es necesario indicar que invité a ser parte de la investigación a todas las estudiantes de Licenciatura (14 en total) y cuatro estuvieron en la disposición de participar. Debido a esto, decidí tomar en cuenta a las estudiantes del último nivel de Bachillerato que están trabajando y, de las siete que están trabajando, cuatro aceptaron ser parte de la investigación. Me acompañaron, en resumen, un total de ocho estudiantes.

\section{Encuentros para aprender y construir juntas}

Después de hacer referencia a las compañeras de viaje, es necesario compartir y dar a conocer esos encuentros para aprender y construir juntas, los cuales son los que permiten la construcción de la investigación y la transformación personal y profesional de todas. De este modo, menciono cuatro aspectos importantes de la investigación: tema, problema, propósito general y propósitos específicos.

\section{Tema}

Perspectiva de un grupo de estudiantes de Bachillerato y Licenciatura de la DEB sobre la pertinencia del Plan de Estudios de la Carrera de Pedagogía con énfasis en Educación Preescolar, con respecto a la formación de docentes de educación preescolar para la atención educativa de niñas y niños menores de cinco años.

\section{Problema}

¿Qué pertinencia tiene el Plan de Estudios de la Carrera de Pedagogía con énfasis en Educación Preescolar, para la formación de docentes de educación preescolar en la atención educativa de niñas y niños menores de cinco años, desde la perspectiva de estudiantes de Bachillerato y Licenciatura de la DEB?

\section{Propósito general}

Analizar, desde la perspectiva de un grupo de estudiantes de Bachillerato y Licenciatura de la DEB, qué pertinencia tiene el Plan de Estudios de la Carrera de Pedagogía con énfasis en Educación Preescolar, para la formación de docentes de educación preescolar en la atención educativa de niñas y niños menores de cinco años.

\section{Propósitos específicos}

1. Identificar, mediante conversatorios, los componentes principales del Plan de Estudios de la Carrera de Pedagogía con énfasis en Educación Preescolar, focalizando en la formación de 
docentes de educación preescolar en cuanto a la atención educativa de niñas y niños menores de cinco años.

2. Reflexionar, en grupos focales, sobre la perspectiva de un grupo de estudiantes de Bachillerato y Licenciatura de la DEB sobre la pertinencia de los componentes del Plan de Estudios de la Carrera de Pedagogía con énfasis en Educación Preescolar, para la formación de docentes de educación preescolar en la atención educativa de niñas y niños menores de cinco años.

3. Proponer nodos relacionados con la formación de docentes de educación preescolar en cuanto a la atención educativa de niñas y niños menores de cinco años, que sean útiles para un fortalecimiento del Plan de Estudios de la Carrera de Pedagogía con énfasis en Educación Preescolar.

De lo anterior, se desprende que mi propuesta de acción se basa en propiciar encuentros con estudiantes, para reflexionar sobre la pertinencia del Plan de Estudios en la formación docente para niños menores de cinco años. Se trata de que, en estos encuentros, podamos dialogar, opinar, escucharnos, equivocarnos, relacionarnos, conocernos y entre otras cosas, cuestionarnos. Son encuentros para crecer, para transformarnos y para irnos construyendo entre nosotras mismas, construir haciendo, el cambio se produce desde cada encuentro y a la postre se podrán documentar propuestas concretas de cambio al Plan de Estudios.

Estos encuentros serán analizados en toda su integralidad, es decir, como investigadora aprendiente, tengo la intención de leer estos encuentros con el corazón, con todas las sinfonías de la música que ahí se va a generar: contenidos manifiestos y latentes desde la perspectiva personal primero y la colectiva en un segundo momento de objetivación (Olson, s. f.).

Hasta el momento se han generado diferentes encuentros. Es importante mencionar que estos corresponden al primer propósito específico de la investigación, sin que ello implique que lo que aquí se genere no tenga relación con el segundo o tercer propósito específico. Recordemos que al ser una investigación dentro de un enfoque de investigación acción, todo se va construyendo poco a poco, los colores, los sonidos, los aromas, se conjugan de diferentes maneras para crear procesos y esencias variadas. Son estas conjugaciones, pienso yo, caracterizadas por la incertidumbre, la confusión, la creación permanente, las que permiten una verdadera transformación en las personas que participan de un proceso de investigación. Seguidamente, el detalle de los encuentros que hasta el momento se han realizado.

Encuentro $N^{\circ} 1$ con la investigadora: Un encuentro conmigo misma: ¿quién soy?, ¿qué quiero?, ¿qué pienso?, ¿qué surge a partir de mi trabajo?

Al enfrentarme al reto de tener que comenzar un trabajo final de graduación en un momento de cambios y situaciones importantes en mi vida, empiezo a pensar en posibilidades que estén a mi alcance y que me den certezas y seguridades. No es raro que pensara de esta manera, pues estas características, sumadas a la estructura rigurosa, han sido aspectos a los que me he aferrado en muchos ámbitos de mi vida, principalmente en el laboral, aunque debo reconocer que en cosas triviales, me doy cuenta de que las estructuras me acompañan.

Dichosamente, aunque sigo evidenciando estas características de alguna u otra forma, me he topado en mi camino con personas que me "han movido el piso", que han movido mis estructuras 
y así, poco a poco, estoy en un proceso de cambio y transformación que, si tengo que resumirlo, lo resumiría en "soltar", en "sentirme libre", en "sentirme liviana". Insisto una vez más, esto no solamente está teniendo un impacto en mi desempeño laboral, sino que en mi vida personal también y, así, estoy aprendiendo a tener una calidad de vida, llena de emociones, de tiempos y momentos valiosos, de aprender a dar prioridad a lo que verdaderamente es importante. Reconozco que me sigue costando saborear las distintas cosas con calma, pero el proceso de transformación inició y eso ya es algo positivo en mi vida. Al final de cuentas, un proceso tal no se concreta de la noche a la mañana, y disfrutar que no todo sea tan rápido también es muy gratificante.

Así, puedo afirmar que el impacto que el proceso de desarrollo de esta investigación ha tenido en mí como persona es parte de esos encuentros del cambio y para él, porque todo inicia por mí, todo pasa por quién soy yo y cuál es mi esencia. Podría decir, además, que este primer acercamiento conmigo misma es una primera fase de diagnóstico o un primer encuentro de autoconocimiento. Sumado a lo cual cabe destacar que la fase de diagnóstico o de conocer hacia dónde voy con mi investigación inició desde que empecé a tener la inquietud del problema de investigación: en los espacios de reflexión de la DEB, en los momentos de conversación informales con colegas, en los espacios de reflexión con la coordinadora de la maestría, a partir de las manifestaciones de las estudiantes en los diferentes cursos que he impartido y, por supuesto, con base en mi experiencia personal como profesional formada en esta carrera.

Todos estos acercamientos me han permitido hacerme una idea de qué es lo que quiero y hacia dónde quiero encaminarme y, como bien se puede apreciar, no son momentos encapsulados en casillas separadas, se han dado de forma simultánea, y aún se siguen dando, por esa razón, podría afirmar que más que una fase de diagnóstico concebida como un momento específico al inicio de la investigación, podría llamarla una fase de saber hacia dónde voy, por dónde voy y con quiénes voy. No está acabada, se sigue construyendo. De esta manera, una vez que tuve un encuentro conmigo misma, se dio un primer encuentro con las estudiantes.

\section{Encuentro $N^{\circ} 1$ con las estudiantes: Invitación para aprender y construir juntas}

Después de que las estudiantes estuvieron de acuerdo, voluntariamente, en participar de la investigación, empecé a pensar en una posibilidad para que todas pudiéramos reunirnos y, así, ellas conocieran más sobre de qué se trataba la investigación. Debo decir que, desde el momento en que empecé a visualizar este encuentro, pensé en algún documento escrito para entregarles a las estudiantes y, una vez más, mis estructuras y rigidez salieron a la luz: en un primer momento, en vez de llamar "encuentro" a estos acercamientos, los denominé "reunión" y de pronto me vi a mí misma analizando cada una de estas palabras. "Reunión" me sonaba como algo más impersonal, como una cita para hablar de algo y listo, por el contrario "encuentro" implicaba un acercamiento más personal, un encuentro de esencias, de colores, de miedos, de dudas, de lo que en realidad somos cada una; por esta razón, decidí titular los acercamientos de esta manera. Es evidente, también, cómo la transformación personal sigue siendo una constante en todo el proceso (Olson, s. f.).

Este primer encuentro lo llevamos a cabo un día en la tarde, las estudiantes de Bachillerato tuvieron que llegar antes a la Universidad, porque debían asistir a clases ese mismo día, dos horas después de la cita y las estudiantes de Licenciatura, no tenían que ir ese día a la Universidad. Una 
vez más salta a la vista la importancia de que este sea un proceso voluntario y no obligatorio: sin problema acudieron a la Universidad únicamente a la convocatoria que yo les había hecho.

Para comenzar, nos presentamos, titulé a esta parte "una mirada hacia nosotras", hubo un ambiente un poco tenso al inicio, ya que entre sí las estudiantes de Bachillerato y Licenciatura no se conocían. Sin embargo, poco a poco todas (inclusive yo) nos fuimos sintiendo en libertad de opinar, de hablar y compartir con las demás. Les entregué un documento escrito, en el que se detallaba lo que íbamos a hacer en ese tiempo de encuentro, en este documento se planteaba lo siguiente:

a) Una mirada hacia nosotras: consistió en realizar una presentación en la cual describíamos quiénes éramos y qué hacíamos.

b) Reflexión: “QQué era lo realmente importante en nuestra clase?” (Toro, 2005).

c) ¿Por qué estamos aquí?: les expliqué las razones por las cuales las había tomado en cuenta a ellas.

d) Conociendo sobre la propuesta: presenté el tema, el problema, los propósitos y las premisas de la investigación.

e) Construyamos juntas: se basó en el conversatorio que, como tal, desarrollamos juntas.

Como bien lo mencioné anteriormente, después de la presentación, continuamos con una reflexión del libro de Toro (2005) "Educar con co-razón”, la cual hace referencia al "acontecimiento y al encuentro". La leímos y comentamos, sin embargo, no tuvo el impacto que yo esperaba, ya que las estudiantes no aportaron ni participaron tanto como yo me lo imaginaba. Particularmente este libro, para mí, había tenido un gran significado, ya que se relaciona con la esencia del ser docente, sin embargo, lo que compartí con ellas, a mi juicio, no tuvo tanta relevancia por la razón antes mencionada. Entonces, me doy cuenta de otra característica de la investigación-acción: es un proceso que toca y transforma a cada persona de manera distinta, que tiene resultados diferentes de los que uno se espera y que nada absolutamente se puede dar por acabado o supuesto (Elliot 2005), todo depende de quiénes son y qué piensan los sujetos participantes.

Es entonces cuando cobra relevancia la calidad de las relaciones, el nivel de reconocimiento de los demás y los encuentros con los otros, aspectos que destaca Toro (2005). Además de esto, otro elemento que juega un papel relevante dentro de una investigación-acción tiene que ver, siguiendo con el mismo autor, con los acontecimientos, los cuales le dan significado a los procesos y contribuyen a la transformación e impacto en los diferentes sujetos participantes de la misma. Al respecto, Toro (2005) manifiesta que:

El acontecimiento no se podía codificar como una situación prefabricada para la que ya se tenían soluciones prefijadas o preestablecidas. El acontecimiento es siempre una situación que se presenta, una situación presente y, por consiguiente una situación "que se nos regala". (...) La pedagogía del acontecimiento permite una educación "desde lo imprevisto", frente a esa otra pedagogía preprogramada en la que las mismas causas o propuestas provocan los mismos efectos, producen siempre los mismos resultados. Una consideración pedagógica del acontecimiento va a alcanzar, superar e incluso trascender o ir más allá de los objetivos iniciales de partida y es la que mejor puede favorecer el que cada uno pueda extraer "lo que puede y a su ritmo" de una situación dada, cada cual desde su particular nivel evolutivo o grado de conciencia. (p. 42) 
Este planteamiento del autor, de la pedagogía del acontecimiento, es lo que de alguna u otra manera pretendía propiciar a partir del encuentro con mis estudiantes. De este modo, después de la reflexión que hicimos juntas, compartí con ellas algunos elementos importantes de la investigación como el problema y los propósitos y, luego de escucharme, abrimos el espacio para que dijeran todo lo que pensaban en torno al problema de investigación. Todas empezaron a aportar y a opinar, les entregué un papel periódico y un marcador, una estudiante escribía lo que las demás compañeras iban diciendo, yo iba tomando mis apuntes y hubo oportunidad para que todas participáramos, se dieron, entonces, diferentes situaciones en este encuentro:

- Unas estudiantes por sus características particulares (más tímidas o más extrovertidas) hablaron más que otras.

- Empezaron a interactuar las estudiantes de Bachillerato y de Licenciatura, y empezaron a buscar puntos de encuentro y desencuentro en la formación que habían recibido.

- Después de un momento de aparente tensión hacia lo desconocido y hacia las personas desconocidas, empezaron a sentirse identificadas en lo que decían. Se apoyaban unas a otras y reforzaban entre sí sus comentarios.

- Las risas entre ellas fueron evidentes.

- Yo tenía un poco de miedo hacia lo que iba a suceder, me posicioné como una compañera y colega más, que aportó, escuchó y opinó. Sin duda alguna, lo que ellas comentaban, me hacía reflexionar en lo que yo como académica estaba haciendo a partir de mis cursos.

- La estudiante que escribía tomó la iniciativa de hacerlo de una forma particular, pero escribía menos de lo que todas hablaban y aportaban, porque ella también aportó y participó mucho.

- Debido a lo anterior, yo iba haciendo mis comentarios, pero hice un esfuerzo por tratar de anotar todo lo que iban diciendo.

- La conversación giró en torno al tema, es decir, a las necesidades que han sentido en su formación, pero surgieron comentarios y reflexiones sobre otras condiciones que para ellas también son relevantes y que, a mi criterio, no están directamente relacionadas con el tema, pero tienen que ver con él.

- El tiempo "formal" de presentación y de explicación de mi trabajo final de graduación fue un poco incómodo para mí, ellas estaban escuchándome, pero en el momento de compartir me sentí libre y ellas establecieron sus propias interacciones entre sí.

De este modo, puedo empezar a visualizar una escena completa en este encuentro de una hora y media de duración, es decir, no solamente lo que se dice es relevante, sino ¿qué se dice?, ¿cómo se dice?, ¿por qué se dice?, ¿en qué espacio se dice? y ¿a quiénes se dice?, todo esto forma parte de la investigación.

Puedo concluir, entonces, que este primer encuentro con las estudiantes consistió en un grupo focal (Amezcua, 2003), ya que todas opinaron e interactuaron a partir de un núcleo generador. Como bien lo he venido mencionando, este primer encuentro es un primer acercamiento y, por lo tanto, es el primer paso para seguir construyendo en otros encuentros, ya que como lo menciona Olson (s. f.), la investigación acción es un constante hacer y rehacer. 


\section{Reflexiones finales}

A partir del encuentro y acercamiento de reflexión vivido con las estudiantes, todas juntas estamos experimentando transformaciones a corto plazo. Se generó un tiempo y un espacio en el que compartimos juntas y el cual implicó conocernos, escucharnos, despojarnos de creencias y miedos, así como darnos cuenta de que no estamos solas en lo que hacemos y que existen más coincidencias que discrepancias entre nosotras. Esto ya puede considerarse como un primer impacto de la investigación a corto plazo.

Por otra parte, se pretende que entre todas vamos a construir nodos de reflexión relacionados con el fortalecimiento del Plan de Estudios de la CPEP. Estas reflexiones conjuntas serán entregadas a las autoridades de la DEB y de la CPEP, para que, si lo consideran pertinente, puedan tomarlos en cuenta para enriquecer los procesos formativos de las estudiantes. Esta sería una visión de mediano plazo.

Una visión de largo o mediano plazo consiste en pensar que estos elementos que se desprenden de la investigación contribuirán a un fortalecimiento del Plan de Estudios de manera formal. Además, otra visión a largo plazo, podría ser el hecho de que, a partir de la investigación, los mismos académicos y académicas de la DEB tomen en cuenta estos insumos para transformar y enriquecer los cursos que imparten en la actualidad.

En relación con lo anterior y como otra visión a corto plazo, cabe señalar que, como investigadora, ya estoy sufriendo un proceso de transformación personal y profesional, por todas las razones de las que hablé al inicio de este documento; pero también porque, a partir de estas oportunidades de diálogo y reflexión, me estoy dando cuenta de que tengo muchos aspectos por mejorar en los cursos que imparto. Resulta imposible no relacionar los comentarios, aportes e inquietudes de las estudiantes con mi función como académica dentro de la CPEP.

De este modo, concluyo con este primer compartir sobre el camino de la transformación individual y colectiva. Me asedian aún muchas preguntas, muchas incertidumbres, así como una gran satisfacción, debido al impacto real que esta investigación está teniendo en mí como persona y como profesional. Cierro, para reflexionar, con una cita de Freire (2005) que me motiva a seguir en movimiento, en transformación, en contradicción, para continuar con el camino del aprendizaje y los cambios en el contexto específico en el que me encuentro inmersa.

Una educación que posibilite al hombre para la discusión valiente de su problemática, de su inserción en esa problemática, que lo advierta de los peligros de su tiempo para que, consciente de ellos, gane la fuerza y el valor de luchar, en lugar de ser arrastrado a la perdición de su propio "yo", sometido a las prescripciones ajenas. Educación que lo coloque en diálogo constante con el otro, que lo predisponga a constantes revisiones, a análisis críticos de sus "descubrimientos", a una cierta rebeldía, en el sentido más humano de la expresión (...). Frente a una sociedad dinámica en transición, no admitimos una educación que lleve al hombre a posiciones quietistas, sino aquellas que lo lleven a procurar la verdad en común, "oyendo, preguntando, investigando (...).” (p. 85)

Continúa el proceso, continúa la aventura, continúa la transformación... 


\section{Referencias bibliográficas}

Amezcua, M. (2003). La entrevista en grupo. Características, tipos y utilidades en investigación cualitativa. Enfermería clínica, 13(2), 46-117. Recuperado de http://www.portalessa.com.ar/ ARCHIVOS2/metodologia de la investigacion/2cuatrimestre/AMEZCUA-La entrevista en grupo..pdf

Blández, J. (2000). La investigación-acción: Un reto para el profesorado. Guía práctica para grupos de trabajo, seminarios y equipos de investigación. (2 ${ }^{\mathrm{a}}$. ed.). Barcelona: INDE Publicaciones.

Dobles, M. C., Zúñiga, M. y García, J. (1998). Investigación en Educación: procesos, interacciones, construcciones. San José, Costa Rica: EUNED.

Elliot, J. (2005). La investigación-acción en educación. (5ª . ed.). Madrid: Ediciones Morata, S. L.

Freire, P. (2005). La educación como práctica de la libertad. Buenos Aires: Siglo XXI Editores Argentina.

Freire, P. (2006). Pedagogía de la indignación (2ª ed.). Madrid: Ediciones Morata.

Jara, O. (1994). Para sistematizar experiencias: Una propuesta teórica y práctica. San José, Costa Rica: Alforja.

Latorre, A. (2007). La investigación-acción. Conocer y cambiar la práctica educativa. (4ª ed.). España: Graó.

Olson, M. (s. f.). La investigación acción entra al aula. USA: Aique.

Peralta, M. V. (2004). En construcción de una pedagogía del siglo XXI. Aportes desde Latinoamérica. Madrid: PIAF.

Starico de Acomo, M. N. (1996). Los proyectos en el aula: Hacia un aprendizaje significativo en la $E G B\left(2^{\circ}\right.$ ed.). Argentina: Magisterio del Río de la Plata.

Toro, J. M. (2005). Educar con “Co-razón” (6 ed.). España: Desclée De Brouwer. 